\title{
Assessing the Impact of an Expanded Scope of Practice for Pharmacists at a Community Hospital
}

\author{
Soomi Hwang, Tamar Koleba, and Vincent H Mabasa
}

\section{INTRODUCTION}

I n 2009, the College of Pharmacists of British Columbia introduced Professional Practice Policy 58, "Protocol for Medication Management-Adapting a Prescription". This policy has enhanced pharmacy practice by allowing pharmacists to make changes to prescriptions. More specifically, it allows pharmacists to change a drug dose or formulation, titrate medications, renew prescriptions, and make drug substitutions within the same therapeutic class in all practice settings. This expansion of pharmaceutical services is in line with the objectives of CSHP 2015, ${ }^{1}$ increasing the extent to which pharmacists, pharmacy departments, and hospitals improve medication safety and help patients to achieve the best use of medications.

An increasing number of published studies are demonstrating that an expanded scope of practice (ESP) for pharmacists improves patient outcomes and enhances pharmacists' job satisfaction. Patient counselling, medication reconciliation (on admission, transfer, or discharge), and supplementary prescribing by pharmacists have been shown to reduce drug-related problems and readmission to hospital, thereby reducing costs for the health care system. ${ }^{2-4}$ In addition, interventions by hospital pharmacists have been linked to reductions in medication errors, medication costs, and length of hospital stay while improving medication adherence, knowledge, and appropriateness of pharmacologic therapy. ${ }^{3,4}$ Mysak and others ${ }^{5}$ developed a proactive practice model to facilitate provision of clinical services by pharmacists, which includes individualizing medication therapy and participating in daily bedside rounds. Those authors found that participating pharmacists felt the model improved job satisfaction and patient safety.

The Clinical Executive Committee of Fraser Health endorsed expanding the scope of practice for pharmacists in 2009, and Burnaby Hospital implemented the ESP on April 1, 2012, with the aim of enhancing the timely delivery of patient care and streamlining medication reconciliation after patient admission. ESP at Burnaby Hospital consists of reordering medications for chronic conditions, initiating over-the-counter medications, changing drug formulations, changing drugs within the same therapeutic class, and titrating medication doses.

This study was undertaken to determine how implementation of ESP affected pharmacy practice and patient care at Burnaby Hospital, in terms of activities performed and associated outcomes, as well as the experiences of pharmacists and physicians. The specific objective of the study was to describe and assess the impact of ESP for pharmacists at Burnaby Hospital. The primary outcomes were a categorization of the types of ESP activities performed by pharmacists and an assessment of clinical, humanistic, and economic outcomes. The secondary outcome was a description of the ESP experiences of pharmacists and the impact of ESP on physicians, as documented by surveys of these groups of healthcare professionals.

\section{METHODS}

This study was a retrospective, observational quality assessment study conducted at Burnaby Hospital, a community hospital with approximately 300 inpatient beds. The hospital's 12 full-time clinical pharmacists provide comprehensive pharmaceutical care to inpatients and outpatients in the acute care setting.

Before the study, all pharmacists at Burnaby Hospital were asked to photocopy all future clinical pharmacy notes (CPNs) documenting ESP and other activities. Only pharmacists working in direct patient care were eligible to participate in ESP, as a full patient assessment had to be performed before any ESP activities were undertaken. A convenience sample of photocopied CPNs written by the pharmacists between April 1 and September 30, 2012, was collected and reviewed by one of 
the authors (S.H.). Each ESP activity was categorized by type and was linked to a presumed outcome by the same author.

CPNs documenting activities that did not fall within the definition of ESP were excluded from this analysis. CPNs for patients in the emergency and intensive care areas of the hospital were also excluded, as team decisions during medical rounds and verbal orders are routine in these practice settings. Patients under the care of hospitalists were excluded, as these physicians are generally available for direct consultation in the patient care units. Thus, the methodology was designed to identify only activities that were performed independently by a pharmacist.

Demographic information about participating pharmacists and the patients under their care were collected. Patients' age and sex, as well as the ward type, were obtained from the electronic patient health record at Burnaby Hospital. Anonymous surveys for pharmacists and physicians were created to assess level of formal training, number of years in hospital practice, and impact of ESP on health care practice. Surveys for pharmacists were distributed during a meeting of pharmacists. Physicians who were exposed to ESP to a reasonable degree were selected for the survey. Surveys for physicians were distributed by pharmacists.

Each ESP activity in this study was associated with at least one humanistic, economic, or clinical outcome by one of the study authors (S.H.) on the basis of information provided in the CPNs. Each ESP outcome was determined on the basis of the pharmacist's documentation of the patient assessment and therapeutic plan. Humanistic outcomes were related to activities that improved patient comfort or simplified dosing, such as ordering a medication for symptomatic treatment or changing from an IV to an oral formulation. Documentation that the pharmacist spoke to the patient was required for humanistic outcomes. Economic outcomes were subcategorized as reduced cost for the hospital, for the patient, or for both hospital and patient. Hospital costs were deemed to have been reduced if a medication initiated in the hospital was discontinued, if an IV formulation was changed to an oral formulation, or if changing a medication within a therapeutic class lowered the cost. Patient costs were deemed to have been reduced if the pharmacist discontinued an unnecessary medication for a chronic condition and it was not reinitiated during the hospital admission. Costs were deemed to have been reduced for both hospital and patient if a medication that the patient had been taking both before and during the admission was discontinued. Clinical outcomes included improved effectiveness, such as increasing the dose if the initial dose was too low or reordering medications for chronic conditions; improved safety, such as lowering the dose if the initial dose was too high or discontinuing unnecessary medication; and addition of a required drug, if the pharmacist ordered a new over-the-counter medication to reduce risk factors or for acute symptomatic treatment.

\section{RESULTS}

A total of 227 CPNs written by 11 clinical pharmacists were reviewed. These CPNs documented 194 activities that met the inclusion criteria (Table 1) and 73 activities that were excluded. Of the 194 activities, 135 (69.6\%) involved titrating medication doses, which included increasing or decreasing doses, temporarily holding or discontinuing a medication, renal dosing, and pharmacokinetic dosing of vancomycin and phenytoin (Figure 1). Vancomycin dosing was the most frequent activity related to titration of medication doses (42 [31.1\%] of 135 titration activities).

Long-term medications for chronic conditions were reordered by a pharmacist most frequently in the surgical, medical, and psychiatric wards (Table 2). Of the 34 patients for whom long-term medications were reordered, $11(32 \%)$ were on a surgical ward, $10(29 \%)$ were on a medical ward, and $9(26 \%)$ were on a psychiatric ward.

Of the 73 excluded activities, 55 involved no change to therapy after the pharmacist had assessed and monitored the patient. Eight of these activities were not initiated at the time of documentation, as further monitoring was required before any modification to therapy. Nine of the activities did not fall within the ESP definition, including counselling and medication clarification. One CPN was incomplete.

A total of 211 outcomes were identified. The majority of the outcomes (172 [81.5\%]) were deemed to have enhanced clinical outcomes of the patient (Table 3). More specifically, 95 of these outcomes resulted from improving the effectiveness of pharmacologic therapy and 75 from improving its safety.

Eight of the 11 pharmacists responded to the survey. The responding pharmacists had working experience that ranged from less than 5 years to more than 20 years. Three of the pharmacists had a bachelor of pharmacy degree, 3 had additional hospital residency training, and $3 \mathrm{had}$ a postgraduate Doctor of Pharmacy degree. All of the pharmacists either agreed or strongly agreed that implementation of ESP had improved the overall quality of comprehensive patient care, and 7 pharmacists agreed or strongly agreed that ESP had enhanced their autonomy and recognition for patient care (Table 4). Two pharmacists did not feel comfortable performing all activities within the ESP. Lack of time was identified as a barrier to ESP

\section{Table 1. Activities under the Expanded Scope of Practice}

\begin{tabular}{lrr} 
& $\begin{array}{c}\text { No. (\%) of } \\
\text { Activities }\end{array}$ \\
\hline Titrating medication doses & $135(69.6)$ \\
Reordering medications for chronic conditions & $39(20.1)$ \\
Initiating over-the-counter medications & 8 & $(4.1)$ \\
Changing drug formulations & 8 & $(4.1)$ \\
Changing medications within therapeutic class & 4 & $(2.1)$ \\
\hline
\end{tabular}




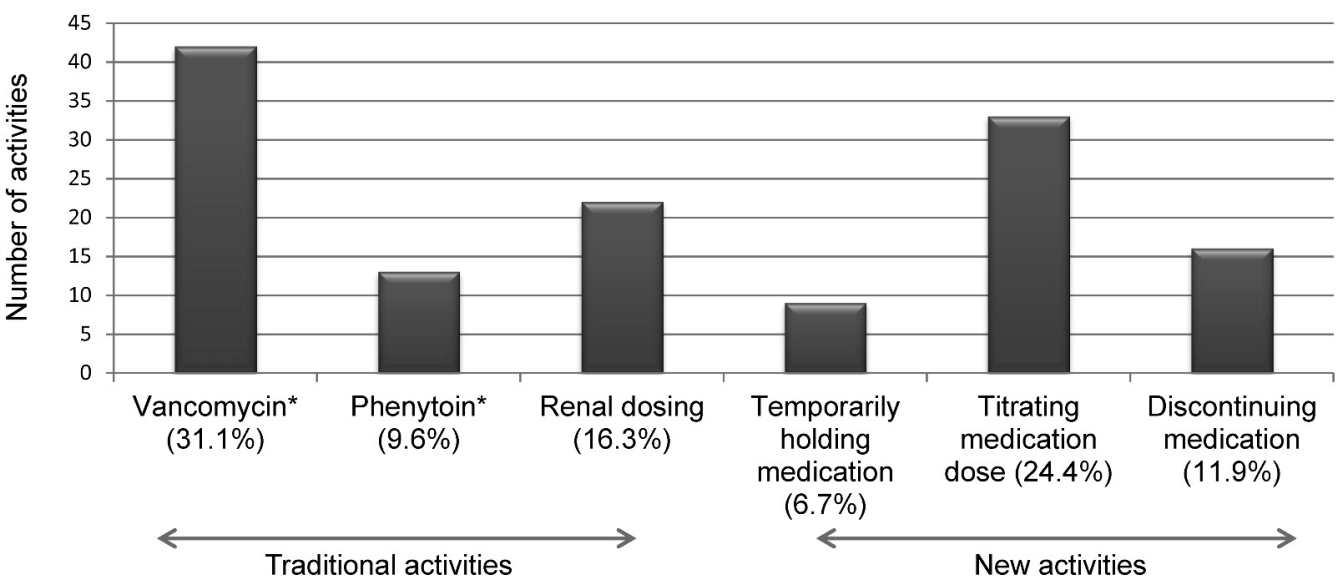

Figure 1. Frequency of activities related to titration of medication doses $(n=135)$, including increasing or decreasing doses, temporarily holding or discontinuing a medication, renal dosing, and pharmacokinetic dosing of vancomycin and phenytoin (where bars for these 2 drugs represent activities of discontinuing, holding, titrating, and renal dosing).

Table 2. Data for Patients Included in the Study

\begin{tabular}{lc} 
Characteristic & No. of Patients* \\
\hline Demographic & \\
Age (years) & 18-99 (mean 68.7) \\
Sex, no. (\%) male & $133(58.5)$ \\
\hline Ward & 129 \\
Medicine & 39 \\
Surgery & 17 \\
Psychiatry & 16 \\
Geriatrics & 12 \\
Cardiology & 11 \\
Stroke & 6 \\
Palliative care &
\end{tabular}

*Except where indicated otherwise.

by 7 pharmacists, while 4 noted lack of experience and 2 suggested lack of opportunities as barriers. One pharmacist commented that "work[ing] with a hospital [staff member] who doesn't want expanded scope of practice" was a barrier. Additional comments about ESP included "Hope to improve. Team help will be good" and "... employer should pay pharmacy for this service as it affects patient care".

A total of 30 surveys were distributed to physicians who worked directly with clinical pharmacists, and 14 surveys were returned. The responding physicians' working experience ranged from less than 5 years to more than 20 years, and half of the respondents had 11 to 20 years of working experience. Three physicians worked on a surgical ward, 4 on an internal medicine ward, and 7 on a psychiatric ward. All physicians either agreed or strongly agreed that implementation of ESP had improved the quality of comprehensive patient care (Table 5). Eight of the 14 physicians had not encountered a situation in which they disagreed with a pharmacist's ESP action. Four
Table 3. Outcomes of Expanded Scope of Practice Activities Documented by Pharmacists

\begin{tabular}{lrr} 
Category & No. (\%) of Outcomes \\
& \multicolumn{2}{c}{$(\boldsymbol{n}=\mathbf{2 1 1})$} \\
\hline Humanistic & $\mathbf{1 7}$ & $\mathbf{( 8 . 1 )}$ \\
Improved patient comfort & 16 & $(7.6)$ \\
Simplified dosing & 1 & $(0.5)$ \\
\hline Clinical & $\mathbf{1 7 2}$ & $\mathbf{( 8 1 . 5 )}$ \\
Improved effectiveness & 95 & $(45.0)$ \\
Improved safety & 75 & $(35.5)$ \\
Addition of a required drug & 2 & $(0.9)$ \\
\hline Economic & $\mathbf{2 2}$ & $\mathbf{( 1 0 . 4 )}$ \\
Reduced cost for hospital & 14 & $(6.6)$ \\
Reduced cost for patient & 4 & $(1.9)$ \\
Reduced cost for hospital and patient & 4 & $(1.9)$ \\
\hline
\end{tabular}

physicians indicated that they had disagreed with some pharmacists' actions, making the following comments: "I have disagreed sometimes with suggestions that were made, usually because of some other medical or social conflict of the patient's case"; "Sometimes I don't agree with suggested change in dosing of antihypertensive or antibiotics. If this is the case then I just order what I want to"; "dosage/frequency of the drug easily restored with communication"; and "antibiotics (rare)".

\section{DISCUSSION}

Since implementation of ESP, pharmacists at Burnaby Hospital have provided new patient care services, such as reordering medications for chronic conditions and titrating medications such as blood pressure and insulin therapy, while continuing to provide traditional services, such as renal dosing services. Although lack of time was the biggest barrier to 
Table 4. Results of Survey of Pharmacists

\begin{tabular}{|c|c|c|c|c|c|c|}
\hline Statement & $\begin{array}{l}\text { Strongly } \\
\text { Agree (5) }\end{array}$ & $\begin{array}{l}\text { Agree } \\
\text { (4) }\end{array}$ & $\begin{array}{l}\text { Neutral } \\
\text { (3) }\end{array}$ & $\begin{array}{l}\text { Disagree } \\
(2)\end{array}$ & $\begin{array}{c}\text { Strongly } \\
\text { Disagree (1) }\end{array}$ & Rank* \\
\hline \multicolumn{7}{|c|}{ Implementation of expanded scope of practice has: } \\
\hline Improved overall quality of comprehensive patient care & 4 & 4 & 0 & 0 & 0 & 1 \\
\hline $\begin{array}{l}\text { Enhanced recognition of pharmacists for autonomy } \\
\text { and patient care }\end{array}$ & 4 & 3 & 1 & 0 & 0 & 2 \\
\hline Enhanced timely delivery of patient care & 3 & 4 & 1 & 0 & 0 & 3 \\
\hline $\begin{array}{l}\text { Increased percentage of my work time available for } \\
\text { clinical activities }\end{array}$ & 3 & $1+$ & 4 & 0 & 0 & 4 \\
\hline $\begin{array}{l}\text { Provided more opportunities for my personal } \\
\text { interactions with patients }\end{array}$ & 2 & 5 & 1 & 0 & 0 & 5 \\
\hline $\begin{array}{l}\text { Increased monitoring for patients (lab values, signs } \\
\text { and symptoms) }\end{array}$ & 2 & 5 & 1 & 0 & 0 & 5 \\
\hline $\begin{array}{l}\text { Increased my interactions with other health care } \\
\text { professionals }\end{array}$ & 1 & 4 & 3 & 0 & 0 & 6 \\
\hline $\begin{array}{l}\text { Improved my relationships with other health care } \\
\text { professionals }\end{array}$ & 1 & 5 & 2 & 0 & 0 & 7 \\
\hline Improved global job satisfaction & 1 & 5 & 2 & 0 & 0 & 7 \\
\hline Encouraged me to enhance my continued education & 1 & 6 & 1 & 0 & 0 & 8 \\
\hline $\begin{array}{l}\text { I feel comfortable performing all activities outlined by } \\
\text { the expanded scope of practice }\end{array}$ & 1 & $5 \neq$ & 0 & 2 & 0 & 9 \\
\hline
\end{tabular}

*Ranking is based on percentage of respondents who agreed or strongly agreed with the statement.

†Numeric response was 3.5 .

\#Includes one person with numeric response of 3.5 .

\section{Table 5. Results of Survey of Physicians}

\begin{tabular}{|c|c|c|c|c|c|c|}
\hline Statement & $\begin{array}{l}\text { Strongly } \\
\text { Agree (5) }\end{array}$ & $\begin{array}{l}\text { Agree } \\
\text { (4) }\end{array}$ & $\begin{array}{l}\text { Neutral } \\
\text { (3) }\end{array}$ & $\begin{array}{l}\text { Disagree } \\
\text { (2) }\end{array}$ & $\begin{array}{l}\text { Strongly } \\
\text { Disagree (1) }\end{array}$ & Rank* \\
\hline \multicolumn{7}{|c|}{ Has implementation of expanded scope of practice: } \\
\hline Improved quality of comprehensive patient care? & 10 & 4 & 0 & 0 & 0 & 1 \\
\hline Enhanced timely delivery of patient care? & 8 & 6 & 0 & 0 & 0 & 2 \\
\hline Improved your relationships with clinical pharmacists? & 7 & 4 & 3 & 0 & 0 & 3 \\
\hline $\begin{array}{l}\text { Improved the quality of your interactions with clinical } \\
\text { pharmacists? }\end{array}$ & 4 & 9 & 1 & 0 & 0 & 4 \\
\hline Improved your understanding of clinical pharmacists' skills? & 4 & 7 & 3 & 0 & 0 & 5 \\
\hline \multicolumn{7}{|l|}{$\begin{array}{l}\text { After pharmacists have performed activities } \\
\text { within the expanded scope of practice: }\end{array}$} \\
\hline $\begin{array}{l}\text { Pharmacists have clearly documented their action(s) } \\
\text { and rationale }\end{array}$ & $\stackrel{3}{\text { must" }} \times 1$ & $\begin{array}{c}3 \\
\text { yes" } \times 5)\end{array}$ & 1 & 0 & 0 & NA \\
\hline
\end{tabular}

*Ranking is based on percentage who agreed or strongly agreed with the question.

performing ESP, both pharmacists and physicians agreed that implementation of this approach had improved patient care, and pharmacists felt recognized for their services.

Reordering medications for chronic conditions occurred most frequently on surgical, medical, and psychiatric wards. Although the large proportion of patients admitted to medical wards may explain the high frequency of ESP activities occurring there, specialized wards, such as surgery and psychiatry, provided pharmacists with opportunities to provide seamless care.

Each activity was linked to one or more clinical, humanistic, and economic outcomes. Since many of the activities involved titrating medications, which can improve the effectiveness or safety of a medication, the majority of the activities were deemed to improve clinical outcomes. This result is consistent with findings in the literature. A study of patients in the perioperative setting found that when pharmacists were responsible for medication reconciliation and were involved in supplementary prescribing, there were significantly fewer missed doses of patients' regular medications during the hospital stay and fewer medication reconciliation charting errors related to dose or frequency, relative to usual care. ${ }^{6}$ According to a systematic review that compared medication reconciliation with usual care, medication reconciliation interventions that heavily involved pharmacy staff reduced medication discrepancies and adverse drug events. ${ }^{?}$ 
Pharmacists in the current study also appeared to contribute to a reduction in hospital and patient costs through discontinuation of unnecessary medications and changes to drug formulations. Similarly, a study at a trauma centre found that clinical pharmacy activities and interventions, including discontinuation of medications, changes to antibiotic therapy, and changes from IV to oral formulations, resulted in significant cost savings, either directly or by preventing adverse drug events. ${ }^{8}$ The current study assessed only direct and immediate medication cost savings; long-term costs were not considered. Increased health care costs due to changes to medications that might have resulted in increased costs, such as therapeutic substitutions and increases in doses, were not considered as an outcome, nor was there any attempt to associate cost savings with a particular dollar value. Law and others ${ }^{9}$ published a study protocol aiming to capture the outcomes of prescription adaptation by community pharmacists in British Columbia, such as changes in drug costs and health care use. Although results of the study itself are not yet available, it is hypothesized that adaptations will reduce total use of health care resources. ${ }^{9}$

Finally, pharmacists at Burnaby Hospital using ESP improved patient comfort and simplified dosing regimens, thereby improving humanistic outcomes. For the purposes of this study, only activities with documentation of pharmacists' discussions with patients could be counted as having a humanistic outcome. As a result, some humanistic outcomes from ESP might not have been captured by this analysis. Additionally, because this was a retrospective study, no follow-up interviews with patients were conducted.

Surveys were used to assess how ESP was perceived by pharmacists and physicians. Both groups thought that ESP improved the quality of patient care and the timeliness of service, helping to streamline medication reconciliation after admission and enhancing timely delivery of patient care. However, pharmacists indicated that lack of professional time was a barrier to full implementation of ESP activities. Pharmacists also tended to agree that this initiative had enhanced recognition of pharmacists' role in patient care and their ability to practice autonomously. This finding is in line with physicians' responses that ESP improved their relationships with clinical pharmacists.

A UK study looking at early pharmacist experiences of supplementary prescribing yielded similar survey results. ${ }^{10}$ Participants identified job satisfaction, increased selfconfidence, greater professional recognition, and time savings as benefits of implementing supplementary prescribing. ${ }^{10}$ However, they also indicated financial and organizational problems and a general lack of awareness of the pharmacist's role as the main barriers to pharmacist prescribing. ${ }^{10}$ Another study of supplementary prescribing by pharmacists found that pharmacists made better use of their existing skills and generat- ed benefits for patients, but barriers to prescribing included lack of remuneration for the expanded role and a lack of continued support. ${ }^{11}$ Together with our results, these studies underline the importance of continued support and funding for pharmacists as they implement a new service.

Physicians seemed to view the ESP initiative positively, with many commenting that it was "very helpful" and allowed "more efficient medication management for patients". Clear documentation seemed to be important, as noted by several physicians. Comments from the physician group suggested that clear documentation of the rationale behind a pharmacist's changes to a patient's medication regimen was important to them. A study of supplementary prescribing by pharmacists in primary and secondary health care settings in Northern Ireland found that both pharmacists and physicians believed that this practice is likely to improve overall patient care, ${ }^{12}$ which corresponds to the feedback in the surveys in the current study.

This study may not have captured all ESP activities during the period of analysis, particularly if activities were not documented or notes were not submitted for review. In addition, a large number of patients - those under the care of hospitalists and those in the emergency department and the intensive care unit-were not included. The relatively small number of ESP activities may be explained by the possibility of slow uptake of the new practice by clinical pharmacists. In addition, only 5 or 6 of the 11 participating pharmacists were working at any given time in the included areas during the study period. The small convenience samples of pharmacists and physicians at Burnaby Hospital may mean that these results are not easily generalizable to other hospital sites. Given the small scope of this study, we chose to report frequencies and did not explore associations among variables.

\section{CONCLUSIONS}

Burnaby Hospital pharmacists integrated ESP activities into their clinical practice with relative ease in a short amount of time. These activities appeared to be associated with improved patient-related clinical and humanistic outcomes, as well as decreased health care costs. Lack of time and lack of confidence in performing some ESP activities were identified as challenges, and it may be helpful for pharmacy departments to provide preparatory training and ongoing professional support to their clinical staff.

\section{References}

1. CSHP 2015 status: goals \& objectives. Ottawa (ON): Canadian Society of Hospital Pharmacists; 2011 May [cited 2013 Feb 2]. Available from: www.cshp.ca/programs/cshp2015/docs/CSHP2015GoalsandObjectives StatusReportMay2011.pdf

2. Beckett RD, Crank CW, Wehmeyer A. Effectiveness and feasibility of pharmacist-led admission medication reconciliation for geriatric patients. $J$ Pharm Pract. 2012;25(2):136-41. 
3. Kaboli PJ, Hoth AB, McClimon BJ, Schnipper JL. Clinical pharmacists and inpatient medical care: a systematic review. Arch Intern Med. 2006; 166(9):955-64

4. Ho BP, Lau TT, Balen RM, Naumann TL, Jewesson PJ. The impact of a pharmacist-managed dosage form conversion service on ciprofloxacin usage at a major Canadian teaching hospital: a pre- and post-intervention study. $B M C$ Health Serv Res. 2005;5:48.

5. Mysak TM, Rodrigue C, Xu J. Care providers' satisfaction with restructured clinical pharmacy services in a tertiary care teaching hospital. Can J Hosp Pharm. 2010;63(2):105-12.

6. Marotti SB, Kerridge RK. A randomised controlled trial of pharmacist medication histories and supplementary prescribing on medication errors in postoperative medications. Anaesth Intensive Care. 2011;39(6):1064-70.

7. Mueller SK, Sponsler KC, Kripalani S, Schinipper JL. Hospital-based medication reconciliation practices. A systematic review. Arch Intern Med. 2012;172(14):1057-69.

8. Hamblin S, Rumbaugh K, Miller R. Prevention of adverse drug events and cost savings associated with PharmD interventions in an academic Level 1 trauma centre: an evidence-based approach. I Trauma Acute Care Surg. 2012;73(6):1484-90.

9. Law MR, Morgan SG, Majumdar SR, Lynd LD, Marra CA. Effects of prescription adaptation by pharmacists. BMC Health Serv Res. 2010;10:313.

10. George J, McCaig D, Bond CM, Cunningham IT, Diack HL, Watson AM, et al. Supplementary prescribing: early experiences of pharmacists in Great Britain. Ann Pharmacother. 2006;40(10):1843-50.

11. Hobson RJ, Sewell GJ. Supplementary prescribing by pharmacists in England. Am J Health Syst Pharm. 2006;63(3):244-53.
12. Lloyd F, Hughes CM. Pharmacists' and mentors' views on the introduction of pharmacist supplementary prescribing: a qualitative evaluation of views and context. Int J Pharm Pract. 2007;15(1):31-3.

Soomi Hwang, BSc(Pharm), was, at the time of the study, a pharmacy student in the Faculty of Pharmaceutical Sciences, University of British Columbia, Vancouver, British Columbia, and is currently a Pharmacy Resident with the Interior Health Authority, Kelowna, British Columbia.

Tamar Koleba, BSc(Pharm), ACPR, PharmD, is Supervisor of Dispensary/Parenteral Services, Burnaby Hospital, Burnaby, British Columbia.

Vincent H Mabasa, BSC(Pharm), ACPR, PharmD, is Coordinator, Clinical Services, Burnaby Hospital, Burnaby, British Columbia. He is also Clinical Associate Professor with the Faculty of Pharmaceutical Sciences, University of British Columbia, Vancouver, British Columbia.

Competing interests: None declared.

Address correspondence to:

Dr Vincent H Mabasa

Burnaby Hospital

3935 Kincaid Street

Burnaby BC V5G 2X6

e-mail: Vincent.mabasa@fraserhealth.ca

\section{Vascular Protection in Patients with Diabetes Admitted for Vascular Surgery in a Canadian Tertiary Care Hospital: Pilot Study: Correction}

In the recently published pilot study on vascular protection for patients with diabetes undergoing vascular surgery, ${ }^{1}$ the name of the study hospital was incorrectly stated, in both abstract and text, as Foothills Hospital, Calgary, Alberta. In fact, the patients underwent surgery at the Peter Lougheed Centre, also in Calgary, and the chart review was conducted there.

\section{Reference}

1. Sunderland $M$, De Jong $M$, Bates $D$. Vascular protection in patients with diabetes admitted for vascular surgery in a Canadian tertiary care hospital: pilot study. Can J Hosp Pharm. 2013;66(4):227-32. 